\title{
Sex-related differences in ventricular remodeling after myocardial infarction
}

\author{
Alberto Aimo ${ }^{\mathrm{a}, \mathrm{b},{ }^{*}, 1}$, Giorgia Panichella ${ }^{\mathrm{a}, 1}$, Andrea Barison ${ }^{\mathrm{a}, \mathrm{b}}$, Silvia Maffei ${ }^{\mathrm{b}}$, Matteo Cameli ${ }^{\mathrm{c}}$, \\ Stefano Coiro ${ }^{\mathrm{d}}$, Flavio D'Ascenzi ${ }^{\mathrm{c}}$, Carlo Di Mario ${ }^{\mathrm{e}}$, Riccardo Liga ${ }^{\mathrm{f}}$, Rossella Marcucci ${ }^{\mathrm{g}}$, \\ Doralisa Morrone $^{\mathrm{f}}$, Iacopo Olivotto ${ }^{\mathrm{h}}$, Isabella Tritto ${ }^{\mathrm{d}}$, Michele Emdin ${ }^{\mathrm{a}} \mathrm{b}$

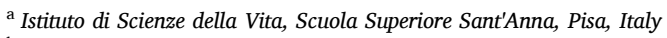 \\ ${ }^{\mathrm{b}}$ Fondazione Toscana Gabriele Monasterio, Pisa, Italy \\ ${ }^{\mathrm{c}}$ Department of Medical Biotechnologies, Section of Cardiology, University of Siena, Italy \\ ${ }^{\mathrm{d}}$ Division of Cardiology, University of Perugia, Italy \\ ${ }^{\text {e }}$ Structural Interventional Cardiology, Careggi University Hospital, Florence, Italy \\ ${ }^{\mathrm{f}}$ Cardio-Thoracic and Vascular Department, University Hospital, Pisa, Italy \\ ${ }^{\mathrm{g}}$ Experimental and Clinical Medicine, University of Florence, Atherothrombotic Center, AOU Careggi, Florence, Italy \\ ${ }^{\mathrm{h}}$ Cardiomiopathy Unit, AOU Careggi, Florence, Italy. Società Italiana di Cardiologia, Sezione Regionale Tosco-Umbra.
}

\section{A R T I C L E I N F O}

\section{Keywords:}

Myocardial infarction

Remodeling

Heart failure

Women

Sex differences

\begin{abstract}
A B S T R A C T
The epidemiology, clinical features and outcome of myocardial infarction (MI) display significant differences between men and women. Prominent sex differences have also been suggested in left ventricular (LV) remodeling after MI. Ventricular remodeling refers to a deterioration of LV geometry and function often leading to heart failure (HF) development and an increased risk of adverse cardiovascular events. Women have a lower propensity to the acquisition of a spherical geometry and LV dysfunction. These differences can be attributed at least partially to a lower frequency of transmural infarction and smaller areas of microvascular obstruction in women, as well as to a less prominent activation of neuroendocrine systems and apoptotic, inflammatory and profibrotic pathways in women. Estrogens might play a role in this difference, which could partially persist even after the menopause because of a persisting intramyocardial synthesis of estrogens in women. Conversely, androgens may exert a detrimental influence. Future studies should better clarify sex differences in the predictors, clinical correlates, prognostic impact and disease mechanisms of remodeling, as well as the existence of sex-specific therapeutic targets. This research effort should hopefully allow to optimize the treatment of MI during the acute and post-acute phase, possibly through different therapeutic strategies in men and women, with the goal of reducing the risk of HF development and improving patient outcome.
\end{abstract}

Cardiovascular disorders have long been regarded as conditions affecting mostly men, but they are the first cause of death among women [1]. Women have a lower incidence of myocardial infarction (MI) than men in all age categories from 35 to 94 years, although the difference between men and women tends to decrease with age [2]. The INTERHEART case-control study demonstrated that women experience their first MI around 9 years later than men. Among the cardiovascular risk factors evaluated, hypertension, diabetes, lack of physical activity and alcohol consumption were more closely associated with the risk of MI among women [3]. In the UK Biobank registry, smoking habit emerged as a stronger predictor of MI among women (hazard ratio [HR] $3.46 \mathrm{vs.}$ 2.23) [4]. Women with MI have a greater prevalence of comorbidities such as diabetes, hypertension and chronic kidney disease [5]. In the younger age categories, women with MI have a significantly higher prevalence of diabetes, rheumatologic disorders and depression than men [5]. Furthermore, women with MI display more often non-ST segment elevation MI (NSTEMI), MI with non-obstructive coronary arteries (MINOCA), and Takotsubo syndrome [6-8]. While plaque rupture represents the main cause of fatal thrombotic occlusion among men (76\%), it was found only in 55\% of cases of fatal MI among women [9].

\footnotetext{
* Corresponding author at: Scuola Superiore Sant'Anna and Fondazione Toscana Gabriele Monasterio, Piazza Martiri della Libertà 33, 56124 Pisa, Italy.

E-mail addresses: a.aimo@santannapisa.it, aimoalb@ftgm.it (A. Aimo).

1 AA and GP contributed equally.
} 
Women are more likely to experience an MI due to non-occlusive mechanisms such as plaque erosion or spontaneous coronary dissection [10-12]. Women have a more severe coronary artery disease [13] and lower infarct sizes [14]. The clinical presentation of MI similarly differs between sexes. Women have more often atypical symptoms ( $42 \%$ vs. $31 \%, \mathrm{p}<0.001$ ) such as pain in abnormal sites (right hemithorax, neck or shoulder, or epigastrium), dyspnea or fatigue [10]. The Variation in Recovery: Role of Gender on Outcomes of Young Acute MI Patients (VIRGO) study demonstrated that women aged less than 55 years have a greater risk of late presentation (over $6 \mathrm{~h}$ from symptom onset) than men ( $35 \%$ vs. $23 \%, \mathrm{p}=0.002$ ). Among possible causes there are the more advanced age, more comorbidities, a higher frequency of atypical symptoms, and possibly also a lower awareness of the MI risk [15]. Women with ST-segment elevation myocardial infarction (STEMI) are revascularized less often $(76.8 \%$ vs. $78.9 \%$; $p<0.001)$ [16] and with longer time delays (door-to-needle time $>30 \mathrm{~min}$ in $55 \%$ vs. $41 \%$ in men) [15]. Percutaneous coronary revascularization is often suboptimal, with a Thrombolysis In Myocardial Infarction (TIMI) score from 0 to 2 in $9 \%$ of women vs. $5 \%$ of men ( $<0.001$ ) [17], possibly because a higher frequency of microvascular dysfunction among women. On the one hand, the higher prevalence of microvascular dysfunction in women has been demonstrated by several angiographic and imaging studies, both in chronic (stable microvascular angina) and in acute conditions (unstable microvascular angina) [18]; on the other hand, some recent studies challenged this notion, reporting a relatively high prevalence of microvascular dysfunction irrespective of sex both in patients with stable angina [19] and in patients with MI [20]. The risk of complications after MI differs as well: women have a greater risk of cardiac rupture, acute mitral regurgitation and cardiogenic shock $[6,21]$. Women also display a higher incidence of major bleeding [22]. Finally, women have a lower likelihood of receiving evidence-based therapies: for example, women are less often started on dual antiplatelet therapy and betablockers within $24 \mathrm{~h}$ from the MI ( $91 \%$ vs. $93 \%$ and $85 \%$ vs. $87 \%$, respectively; both $\mathrm{p}<0.001$ ) [23], and are overall less likely to receive statins, antiplatelet agents, angiotensin converting enzyme inhibitors or angiotensin receptor blockers, and beta-blockers [24].

\section{Left ventricular (LV) remodeling}

\subsection{Epidemiology}

$\mathrm{LV}$ remodeling is a possible long-term complication of MI and consists in a deterioration of LV geometry and function leading to an increased risk of heart failure (HF) and adverse cardiovascular events [25]. LV remodeling is characterized by an increase in LV end-diastolic/ end- systolic volume (LVEDV/LVESV) and a decrease in LV ejection fraction (LVEF). This last is a late phenomenon denoting the exhaustion of the functional reserve of the $\mathrm{LV}$, and is associated with a shorter survival and worse quality of life [25]. LV remodeling is generally defined as a 15-20\% increase in LVEDV, even if alternative definitions have been proposed, such as a $>15 \%$ LVEDV increase and a decrease in LVEF $>3 \%$ within 6 months from a MI [26].

Around one half of patients with STEMI experience LV remodeling (defined as a $>20 \%$ LVEDV increase) within 1 year, more often during the first 3 months from the acute event [27]. In patients with remodeling, the cumulative incidence of HF hospitalization is $6 \%, 7 \%$ and $9 \%$ after 40, 80 and 120 months from a STEMI, respectively, while the incidence is $2 \%, 3 \%$ and $4 \%$ in patients without remodeling, respectively ( $p<0.001$ ) [27]. LV remodeling is associated with a greater risk of mitral regurgitation and ventricular arrhythmias, as well as cardiovascular death $[28,29]$. In a study on 428 patients, the HR of adverse cardiovascular events (death, HF hospitalization, stroke, resuscitated cardiac arrest) was 1.05 (95\% CI 1.01-1.10; $\mathrm{p}=0.015$ ) for each $10 \mathrm{~mL}$ increase in LVEDV, and 1.11 (95\% CI 1.05-1.18; p < 0.001) for each 10 $\mathrm{mL}$ increase in LVESV. A 5 unit decrease in LVEF was associated with a HR of 1.30 (95\% CI 1.14-1.48; p < 0.001) [30].

\subsection{Risk factors for remodeling}

The main risk factors for remodeling are transmural MI (i.e., STEMI), a large infarct area, microvascular obstruction, intramyocardial hemorrhage, and advanced age [31-33]. Some studies reported infarct location in the anterior wall as predictive of remodeling [34,35]. Nonetheless, a recent study demonstrated that anterior MI are usually larger, and that the size of the infarcted area (odds ratio [OR] 1.06; 95\% CI 1.03-1.09; $\mathrm{p}<0.001$ ) is predictive of remodeling, while infarct site is not (OR 1.59; 95\% CI 0.86-2.97; $\mathrm{p}=0.139$ ) [31]. In a cohort of 208 STEMI patients, the following echocardiographic variables emerged as independent predictors of remodeling within 1 year: lower absolute value of global longitudinal strain (HR 0,84, 95\% CI 0.73-0.97; p = 0.020), demonstrating an initial impairment of LV contractility; a shorter mitral valve deceleration time (HR 0.99, 95\% CI 0.98-1.00; $\mathrm{p}=$ 0.023), an early index of diastolic dysfunction; a lower LVEDV at baseline (HR 0.92, 95\% CI 0.90-0.95; p < 0.001), likely because there is more room for LV dilation when the LV is initially smaller [36]. In the same study, a higher peak value of the MB isoform of creatine kinase (HR $1.003,95 \%$ CI $1.000-1.005 ; \mathrm{p}=0.033$ ) emerged as independent predictor of remodeling, likely because of its association with a larger infarct [36].

\subsection{Pathophysiology}

$\mathrm{LV}$ remodeling is promoted by an increased wall stress, the activation of neurohormonal systems, and the inflammatory and fibrotic response to cardiomyocyte loss. LV preload increases shortly after a MI, causing a rise in LV wall stress, and cardiomyocytes in the remote myocardium become hypertrophic to sustain cardiac output [25]. The acute decrease in LV contractility and the increase in cavitary pressures induce the local and systemic activation of neuroendocrine axes, most notably the sympathetic nervous system and the renin-angiotensin-aldosterone system (RAAS). Persistent beta-adrenergic stimulation can lead to an uncoupling between excitation and contraction and the activation of proapoptotic mechanisms. Persistently high catecholamine levels can also induce fibrosis and oxidative damage [37]. Most effects of the RAAS are mediated by angiotensin-II, which has cytotoxic effects on cardiomyocytes, promotes cell hypertrophy and apoptosis, stimulates fibroblast proliferation and induces the synthesis of extracellular matrix (ECM) proteins, mostly by activating the AT1 receptor. Even aldosterone promotes fibroblast proliferation by activating K-Ras-A e MAPK (mitogen-activated protein kinase) 1/2 [38].

Cardiomyocyte necrosis elicits an inflammatory response by activating the complement cascade, inducing the production of reactive oxygen species (ROS) and damage-associated molecular patterns, the latter acting as ligands for pattern recognition receptors such as Toll-like receptors (TLRs). TLR activation promotes the release of proinflammatory cytokines that recruit inflammatory cells in the infarcted area, including neutrophils, monocytes, macrophages, and B- and Tlymphocytes. Tissue leukocytes clear dead cells and fragments of the extracellular matrix, but may also promote the necrosis of still viable cardiomyocytes, thus contributing to scar expansion [39].

After the inflammatory phase, monocytes and macrophages release cytokines and growth factors that suppress inflammation and stimulate vessel formation, fibroblast proliferation and their differentiation into myofibroblasts. These last cells can be activated by transforming growth factor-beta (TGF- $\beta$ ), angiotensin-II, endothelin- 1 and several other factors [40]. In parallel, pro-inflammatory cytokines initially promote a robust activation of matrix metalloproteinases (MMPs), and then of tissue inhibitors of metalloproteinases, inducing ECM degradation and tissue remodeling [41]. As the myocardial scar matures, collagen content progressively increases while leukocytes, vascular cells and fibroblasts are cleared, presumably through apoptosis [42]. Persistent activation of profibrotic pathways can promote infarct expansion and progression to HF. 


\section{LV remodeling: sex differences}

\subsection{Epidemiology}

No significant sex differences in the incidence of remodeling after STEMI have been reported. For example, in a cohort of 1995 patients with STEMI, LV remodeling (defined as a $\geq 20 \%$ increase in LVEDV) occurred within 1 year in $48 \%$ of men and $48 \%$ of women [43]. On the other hand, women represented only $23 \%$ of this cohort [43], and the large underrepresentation of women might have reduced the power to detect significant differences in the prevalence of LV remodeling [14].

Women seem to have a higher risk of HF after MI. For example, in the Valsartan in Acute Myocardial Infarction Trial (VALIANT) study, performed on 14,703 patients, women (31\%) displayed a greater risk of $\mathrm{HF}$ hospitalization within 24 months (HR 1.36, 95\% CI 1.22-1.52; p < 0.001 ) despite the absence of significant sex differences in LVEF and LVEDV from baseline to 20 months ( $\mathrm{p}=0.40 \mathrm{e} \mathrm{p}=0.33$, respectively) [44]. Similarly, an aggregate analysis of 10 randomized clinical trials on STEMI patients showed that women have higher rates of 1-year HF hospitalization than men, regardless of age, baseline LVEF and infarct size [45].

We may summarize our knowledge of post-MI remodeling in women vs. men as follows: 1) women have a lower incidence of MI in all age categories, 2) women with STEMI develop post-MI remodeling with a similar frequency than men, 3) women with MI or those with STEMI have a greater risk of HF. The greater propensity to HF development in women seems partially independent of remodeling and could be attributed to sex differences in age, comorbidities and possibly also treatment of MI [46].

\subsection{Patterns of $L V$ remodeling}

Several preclinical studies established that females develop a less prominent LV remodeling than males after comparable MI events. For example, in a murine model of MI, females displayed a lower LV dilation and a better LV function 12 weeks after an MI [47]. Evidence from clinical studies is limited. In a cohort of 292 patients with prior MI (16\% women) undergoing cardiac magnetic resonance, women showed a trend toward lower LVEDV index values $\left(79 \pm 24 \mathrm{vs} .86 \pm 24 \mathrm{~mL} / \mathrm{m}^{2} ; \mathrm{p}\right.$ $=0.07)$ and a lower LV mass index $\left(64 \pm 18\right.$ vs. $73 \pm 17 \mathrm{mg} / \mathrm{m}^{2} ; \mathrm{p}=$ 0.001 ), as well as higher values of $\operatorname{LVEF}$ ( $53 \pm 14$ rispetto a $50 \pm 14 \%$; $p$ $=0,18)$ and stroke volume $(0.84 \pm 0.18$ vs. $0.72 \pm 0.23 \mathrm{~mL} ; \mathrm{p}=0.008)$ [48]. In a population of 109 patients with STEMI, male sex was predictive of early remodeling (assessing LVEDV evaluated within a few days from the MI event; $p=0.004$ ) and late remodeling (with LVEDV analyzed through a transthoracic echocardiogram 18 months after a STEMI; $p=0.03$ ) [49]. In a series of 50 patients with ischemic HF undergoing heart transplantation, LV mass index and cardiomyocyte volume were significantly lower in women than men [50].

\subsection{Risk factors for remodeling}

Several risk factors for post-MI remodeling display sex differences. As stated above, women are usually older at the time of their first MI and have less often a STEMI than men [6], have smaller infarct sizes $[14,48,51]$ and smaller areas of microvascular obstruction [14]. Indeed, while microvascular dysfunction has been generally reported as a pathophysiological phenomenon occurring more often in women than men [18], microvascular obstruction following MI is a specific condition (also named "no-reflow") whereby myocardial reperfusion is not achieved after a successful epicardial coronary artery recanalization, because of some possible pathogenetic mechanisms including distal atherothrombotic embolization, microvascular ischemic injury, reperfusion injury and preexisting coronary microvascular dysfunction [18]. According to a recent study, microvascular obstruction following STEMI occurred in both sexes with a relatively high frequency (54\% in men vs.
$43 \%$ in women, $\mathrm{p}=0.078)$, with a slightly higher extent in men ( $3 \%$ of $\mathrm{LV}$ mass) than in women $(2 \%, \mathrm{p}=0.04)$ and a slightly higher prevalence of myocardial hemorrhage in men $(45 \%)$ than in women $(29 \%, \mathrm{p}=$ 0.03). Importantly, all these differences were not significant after adjustment for glomerular filtration rate, reperfusion strategy (thrombolysis vs no thrombolysis), culprit artery territory, age and ischemic time [20].

The assessment of clinical, imaging and laboratory variables as predictors of post-MI remodeling is largely incomplete. Circulating levels of B-type natriuretic peptide (BNP) and N-terminal-pro-BNP (NTproBNP) and cardiac troponins predict $\mathrm{LV}$ remodeling after an MI $[52,53]$. In a study on 42 patients with STEMI, baseline levels of NTproBNP emerged as independent predictors of LVEDV increase during the first year after MI $(\mathrm{p}=0.007)$. The $>115 \mathrm{ng} / \mathrm{L}$ NT-proBNP threshold allowed to identify patients developing LV dilation (LVEDV increase $>$ $11.8 \mathrm{~mL}$ ) with $89 \%$ specificity and $68 \%$ sensitivity (area under the curve 0.77) [54]. Even cardiac troponin I measured after 24 to $48 \mathrm{~h}$ after a STEMI emerged as independent predictor of LVEF decline and an increase in LVEDV and LVESV indexed (all p $<0.01$ ), as assessed 5 days and 4 months after an MI [55]. While sex-related differences in the circulating levels of natriuretic peptides and troponins have been demonstrated, as discussed in a dedicated review [56], we are not aware of dedicated analyses of their differential prognostic yield between men and women in the post-MI setting. Conversely, a new biomarker able to predict the progression to LV dysfunction after STEMI in women ( $\mathrm{p}=$ $0.006)$, but not in men ( $p=0.41)$, has been identified. It is the messenger RNA for cyclin-dependent kinase inhibitor 1C (CDKN1C), a regulator of cell proliferation [57].

\subsection{Histology and molecular biology}

In a study on a murine model of MI, females displayed a lower concentration of neutrophils and macrophages in the infarct border zone [47]. A less intense inflammatory response may account for the lower activation of MMPs, the earlier scar formation, lower propensity to infarct scar expansion and cardiac rupture during the first week after an MI, as well as the lower risk of remodeling. A recent study on mice found that infiltration of neutrophils in the infarct zone is less extensive in females, clearing activity of dead cells and tissue debris is more effective in females, and the expression of proinflammatory genes is less pronounced in females [58]. Moreover, females show a less prominent activation of several inflammatory pathways such as the LXR/RXR (liver $\mathrm{X}$ receptors/retinoid X receptor) - NFkB [58,59]. Other pathways seem to be particularly active in males. For example, male mice have a greater expression of TLRs, and TLR knockout blunts the inflammatory response, reduces infarct size and remodeling in males, but not in females [60].

Sex differences in remodeling can be partially explained in terms of apoptosis in the peri-infarcted area. A study on patients dying during the acute phase of MI demonstrated that men have a 10 -fold higher apoptotic index ( $26 \%$ vs. $3 \% ; p=0.003$ ) and a greater expression of the proapoptotic protein Bax in the border zone than women. The apoptotic index in the border zone displayed an inverse correlation with LV wall thickness $(r=-0.48, p=0.029)$, and a direct correlation with the diameter/wall thickness ratio $(r=0.56, p=0.008)$ [61].

\section{Mechanisms of sex differences in post-MI remodeling}

Sex hormones, and in particular estrogens, might influence several mechanisms of the tissue response to MI (Fig. 2), and could then be important determinants of sex differences in ventricular remodeling, even in elderly individuals [62]. Before the menopause, estrogens are synthesized mostly in the ovaries and, to a lesser extent, in the adrenal glands, in testes in males, and in organs and tissues such as bones, adipose tissue, and the heart [63]. Indeed, cardiomyocytes express the aromatase enzyme, which converts androstenedione and testosterone in 
the respective estrogens within the myocardial tissue [64,65]. After the menopause, circulating levels of estrogens decrease drastically, although their effects on the heart might be partially preserved because of this intramyocardial production [62]. Estrogens have genomic and non-genomic effects mediated by the estrogen receptors ER $\alpha, \operatorname{ER} \beta$ and gpER (transmembrane $\mathrm{G}$ protein-coupled estrogen receptor). ER $\alpha$ and ER $\beta$ are transcription factors located in the cytosol, which, upon estrogen binding, translocate into the nucleus where they modulate gene expression by binding ERE (estrogen response elements) sequences. ER $\alpha$ and ER $\beta$, together with gpER (located in the endoplasmic reticulum), can also mediate rapid, non-genomic effects by activating signaling cascades involving phosphatidylinositol-3-kinase and mitogen-activated protein kinases [66]. (See Fig. 1.)

In ovariectomized mice exposed to pressure overload, 17 $\beta$-estradiol (E2) delayed the development of LV hypertrophy [67]. Mice receiving E2 had higher levels of atrial natriuretic peptide [67], which is known to have anti-hypertrophic effects [68]. E2 can also prevent LV remodeling by inducing the production of modulatory calcineurin-interacting protein 1 (MCIP), which then inhibits the pro-hypertrophic calcineurin [69]. Finally, E2 suppresses the production of class I, pro-hypertrophic histone deacetylase (HDAC), while promoting the transcription of class II, anti-hypertrophic HDAC [70]. However, further studies are needed to define the exact mechanisms by which estrogen affects hypertrophy, as E2 seems to have a controversial role depending on the stress stimulus [71] or the genetic background of the experimental animals [72].

E2 also blunts the effects of angiotensin-II on fibroblasts, reducing for example the expression of integrins and MMP-2 [73]. The binding of E2 to ER $\beta$ inhibits the synthesis of TGF- $\beta$ stimulated by endothelin- 1 and angiotensin-II, and then the conversion of fibroblasts into myofibroblasts [74]. Estrogens also inhibit the profibrotic RhoA/ROCK/cofilin pathway through non-genomic mechanisms involving ER $\alpha$ [75]. ER $\beta$ deletion boosts the inflammatory response by enhancing natural killer cells activity and leucocyte extravasation. Estrogens also reduce ROS production by acting on ER $\beta$ [76]. Estrogens also activate the serinethreonine kinase Akt, which inhibits cardiomyocyte apoptosis following an ischemic insult $[77,78]$. Finally, ER $\alpha$ is thought to stimulate the recruitment of endothelial progenitor cells, which promote vessel formation after MI [79].

Testosterone has detrimental effects on post-MI remodeling and promotes LV hypertrophy [80]. Rats undergoing orchiectomy and (1 week later) MI had less LV hypertrophy and better contractility after 8 weeks than rats with MI alone [81]. Testosterone also induces neutrophil infiltration and the expression of p38 and SPAN/JNK, which are associated with the inflammatory response in the heart [82,83], and to an increased risk of cardiac rupture [82]. Testosterone also seems to inhibit the Akt pathway, thus stimulating cardiomyocyte apoptosis and HF development (Fig. 2) [84].

Micro-RNA (miRNA) are small, non-coding nucleic acid molecules. E2 can modulate the production of many miRNA by acting on ERE sequences in gene promoters. Furthermore, the human $X$ chromosome contains $10 \%$ of all miRNAs detected so far, and 118 miRNAs are located on the $X$ chromosome, while only 4 are located on the $\mathrm{Y}$ chromosome. Around $15 \%$ of human X-related genes are not inactivated $[85,86]$, possibly explaining sex differences in normal and disease conditions [87]. For example, miR-98 inhibits apoptosis after MI by blocking the Fas/caspase-3 pathway [88], and hinder angiotensin-II-induced cardiac hypertrophy, partially by inhibiting cyclin D2 [89]. An increased expression of miR-98 because of estrogen stimulation or incomplete $\mathrm{X}$ chromosome inactivation might explain the lower degree of post-MI remodeling in women than men [85].
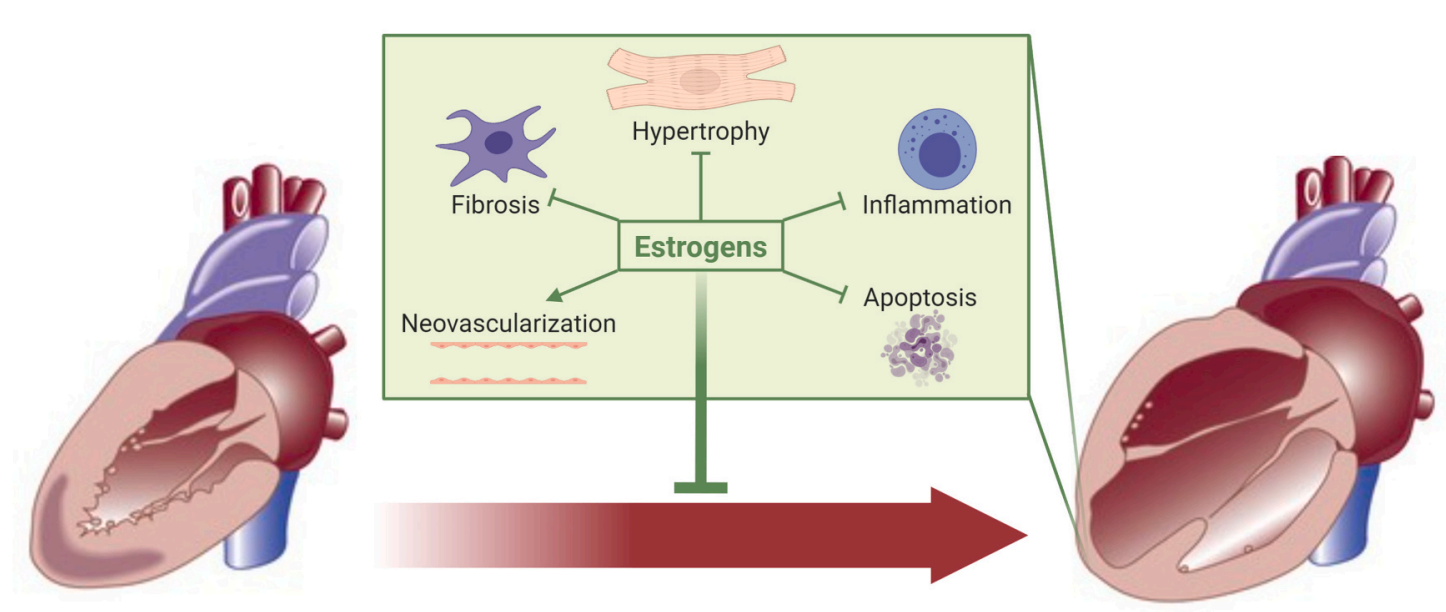

\begin{tabular}{|lr|}
\hline \multicolumn{2}{|c|}{ Myocardial infarction } \\
\hline Incidence & $\mathrm{F}<\mathrm{M}$ \\
STEMI & $\mathrm{F}<\mathrm{M}$ \\
Typical symptoms & $\mathrm{F}<\mathrm{M}$ \\
Infarct size & $\mathrm{F} \leq \mathrm{M}$ \\
Microvascular obstruction & $\mathrm{F}<\mathrm{M}$ \\
Prescription of & \\
evidence-based therapy & $\mathrm{F}<\mathrm{M}$ \\
Age & $\mathrm{F}>\mathrm{M}$ \\
Comorbidities & $\mathrm{F}>\mathrm{M}$ \\
MINOCA & $\mathrm{F}>\mathrm{M}$ \\
Acute complications & $\mathrm{F}>\mathrm{M}$ \\
\hline
\end{tabular}

\begin{tabular}{|l|ll|ll|}
\hline \multicolumn{4}{|c|}{ Ventricular remodeling } \\
\hline Epidemiology & $\begin{array}{l}\text { Macroscopic pattern } \\
\text { and biomarkers }\end{array}$ & Histology \\
\hline Incidence $\mathrm{F} \sim \mathrm{M}$ & LV dilatation & $\mathrm{F}<\mathrm{M}$ & Fibrosis & $\mathrm{F}<\mathrm{M}$ \\
& Systolic dysfunction & $\mathrm{F}<\mathrm{M}$ & Inflammation & $\mathrm{F}<\mathrm{M}$ \\
& Hypertrophy & $\mathrm{F}<\mathrm{M}$ & Apoptosis & $\mathrm{F}<\mathrm{M}$ \\
& $\uparrow$ CDKN1C & $\mathrm{F}$ & & \\
\hline
\end{tabular}

Fig. 1. Sex differences in left ventricular (LV) remodeling after myocardial infarction.

BNP, B-type natriuretic peptide; CDKN1C, cyclin dependent kinase inhibitor 1C; F, females; M, males; MINOCA, myocardial infarction with non-obstructive coronary arteries; NT-proBNP, N-terminal-pro-BNP; STEMI, ST-segment elevation myocardial infarction. 


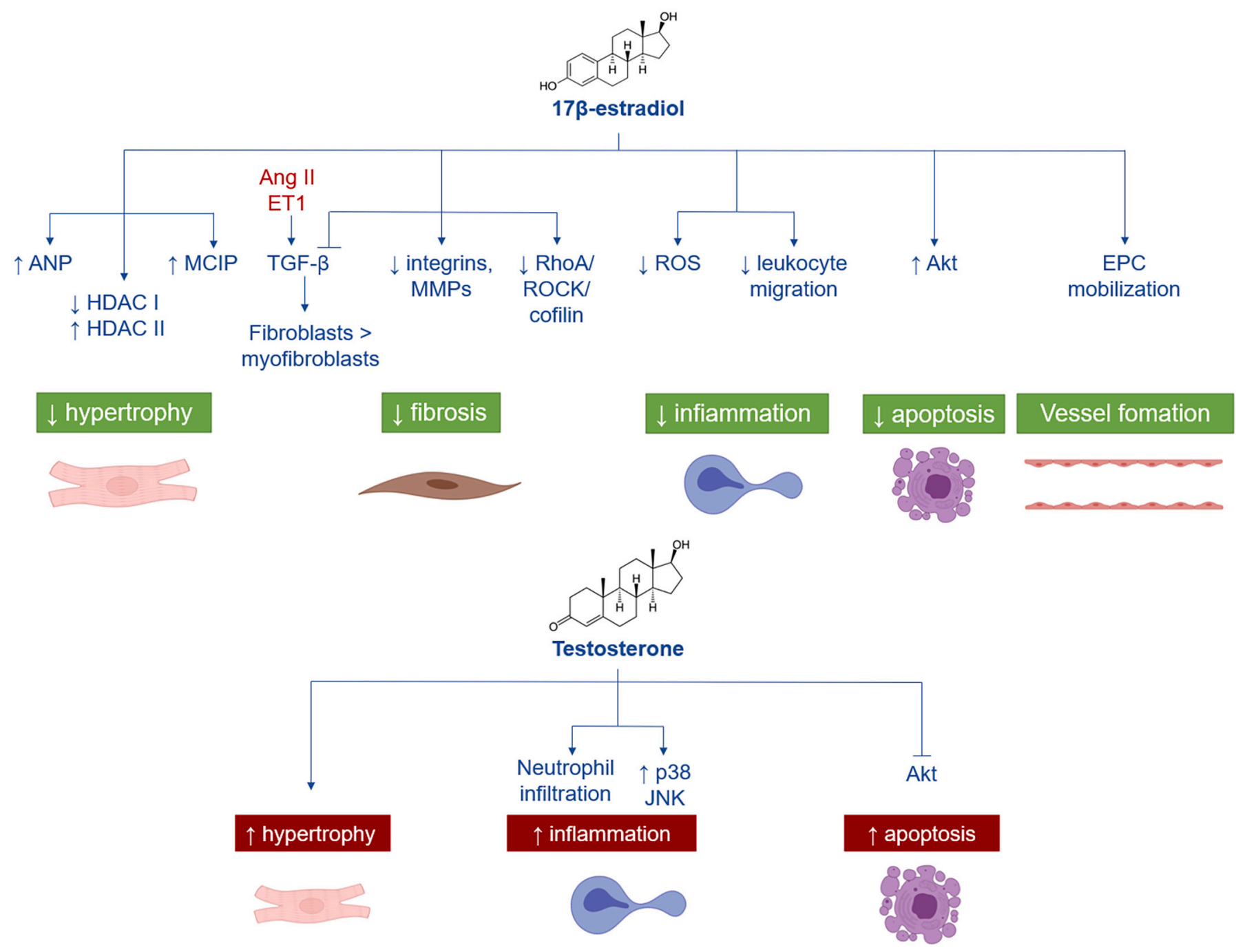

Fig. 2. Effects of sex hormones on the mechanisms of left ventricular remodeling.

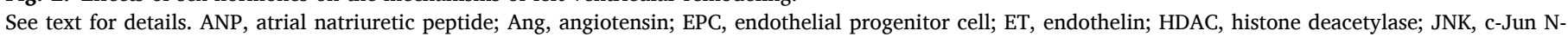

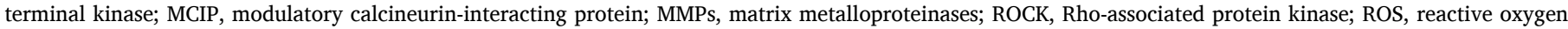
species; TGF- $\beta$, transforming growth factor-beta.

\section{Therapies}

Recommendations about treatment of MI do not differ between men and women because subgroup analyses of randomized controlled trials have not shown any significant differences in drug efficacy between the two sexes [90], with the usual caveat that women have been traditionally underrepresented [91].

The Atherosclerosis Risk in Communities (ARIC) study has analyzed the data of MI hospitalizations from 1995 to 2014 among patients aged between 35 and 54 years. It was found that women have a lower likelihood of receiving lipid-lowering drugs (relative risk [RR] 0.83, 95\% CI 0.80-0.94; $\mathrm{p}<0.001$ ) and dual antiplatelet therapy (RR 0.83, 95\% CI $0.75-0.91 ; \mathrm{p}<0.001)$ than men; this conclusion was confirmed when STEMI or NSTEMI were considered separately [92]. In all age categories, women received less high-dose statins after discharge ( $47 \%$ vs. $56 \%$, respectively) [93]. During a 1-year follow-up of 840 patients with acute coronary syndrome ( $26 \%$ of them women), men were found to be more often on dual antiplatelet therapy than women $(94 \%$ vs. $88 \% ; \mathrm{p}=0.01)$. Ticagrelor was the most used second antiplatelet agent, with no sex differences, while clopidogrel was prescribed more often to women ( $42 \%$ vs. $33 \% ; \mathrm{p}=0.04)$ and prasugrel to men $(17 \%$ vs. $11 \% ; \mathrm{p}=0.04)$. No differences in the rates of major adverse cardiovascular events were recorded [94]. Furthermore, there was no evidence of interaction between sex and bleeding risk after the acute MI phase [95].

Sex differences in the response to mineralocorticoid receptor antagonists (MRAs) were reported. A study on rats found that eplerenone relieves LV dilation and LVEF reduction to a greater extent in females than males [96]. Circulating aldosterone levels are directly correlated with LV wall thickness and LV end-diastolic diameter in women but not in men [97]. Further studies are needed to verify if women and men with MI display a different response to MRAs.

Because of the positive effects of estrogens on the heart and vessels, estrogen therapy (ET) was proposed as a novel approach to the prevention of cardiovascular disease in post-menopausal women. A systematic review of 19 trials on over 40,000 women concluded that ET has minimal or no effects on secondary cardiovascular prevention, while it increases the risk of stroke and thromboembolic events [98]. No data about post-MI remodeling are available.

Finasteride, an inhibitor of conversion of testosterone into the more potent dihydrotestosterone, was evaluated in mice. Animals were treated for 21 days starting 1 week after the MI. Treatment with finasteride reduced the development of systolic dysfunction, LV hypertrophy and fibrosis compared with untreated animals [99].

As for non-pharmacological therapies, sex differences exist in the 
enrolment of patients for cardiac rehabilitation, which might be explained by the higher age of women, the higher percentage of functional dependence, and worse clinical performance at admission in women. Nonetheless, cardiac rehabilitation programs reduce mortality rates, rehospitalization and improve quality of life in both women and men [100].

\section{Conclusions}

Men and women with STEMI show a similar incidence of LV remodeling, although remodeling seems less pronounced in women. This can be explained by a lesser activation of neuroendocrine axes and of pathways promoting LV hypertrophy, fibrosis, inflammation and apoptosis. Sex hormones, both estrogens and androgens, are likely to play a crucial role. Future studies should define more clearly sex differences on predictors of remodeling, its clinical correlates and prognostic impact, as well as its pathophysiological mechanisms and the existence of sex-specific therapeutic targets. This research line should hopefully lead to an optimization of the management of the acute and subacute phases of MI, possibly through differential therapeutic strategies in men and women, with the goal of reducing the likelihood of progression toward HF and improving patient outcomes.

\section{Author statement}

All Authors take responsibility for all aspects of the reliability and freedom from bias of the data presented and their discussed interpretation.

\section{Conflicts of interest}

None.

\section{References}

[1] M. Garcia, S.L. Mulvagh, C.N. Merz, J.E. Buring, J.E. Manson, Cardiovascular disease in women: clinical perspectives, Circ. Res. 118 (8) (2016) 1273-1293.

[2] G. Albrektsen, I. Heuch, M.L. Lochen, D.S. Thelle, T. Wilsgaard, I. Njolstad, et al., Lifelong gender gap in risk of incident myocardial infarction: the Tromso study, JAMA Intern. Med. 176 (11) (2016) 1673-1679.

[3] S.S. Anand, S. Islam, A. Rosengren, M.G. Franzosi, K. Steyn, A.H. Yusufali, et al., Risk factors for myocardial infarction in women and men: insights from the INTERHEART study, Eur. Heart J. 29 (7) (2008) 932-940.

[4] E.R.C. Millett, S.A.E. Peters, M. Woodward, Sex differences in risk factors for myocardial infarction: cohort study of UK biobank participants, BMJ 363 (2018) k4247.

[5] E.M. DeFilippis, B.L. Collins, A. Singh, D.W. Biery, A. Fatima, A. Qamar, et al., Women who experience a myocardial infarction at a young age have worse outcomes compared with men: the Mass General Brigham YOUNG-MI registry, Eur. Heart J. (2020).

[6] J.S. Hochman, J.E. Tamis, T.D. Thompson, W.D. Weaver, H.D. White, F. Van de Werf, et al., Sex, clinical presentation, and outcome in patients with acute coronary syndromes. Global use of strategies to open occluded coronary arteries in acute coronary syndromes IIb investigators, N. Engl. J. Med. 341 (4) (1999) $226-232$.

[7] K. Thygesen, J.S. Alpert, A.S. Jaffe, B.R. Chaitman, J.J. Bax, D.A. Morrow, et al., Fourth universal definition of myocardial infarction (2018), Circulation 138 (20) (2018) e618-e51.

[8] T. Varghese, N.K. Wenger, Non-ST elevation acute coronary syndrome in women and the elderly: recent updates and stones still left unturned, F1000Research (2018) 7.

[9] E. Falk, M. Nakano, J.F. Bentzon, A.V. Finn, R. Virmani, Update on acute coronary syndromes: the pathologists' view, Eur. Heart J. 34 (10) (2013) 719-728.

[10] L.S. Mehta, T.M. Beckie, H.A. DeVon, C.L. Grines, H.M. Krumholz, M.N. Johnson, et al., Acute myocardial infarction in women: a scientific statement from the American Heart Association, Circulation 133 (9) (2016) 916-947.

[11] A. Aziz, H.S. Hansen, U. Sechtem, E. Prescott, P. Ong, Sex-related differences in vasomotor function in patients with angina and unobstructed coronary arteries, J. Am. Coll. Cardiol. 70 (19) (2017) 2349-2358.

[12] J. Saw, E. Aymong, T. Sedlak, C.E. Buller, A. Starovoytov, D. Ricci, et al., Spontaneous coronary artery dissection: association with predisposing arteriopathies and precipitating stressors and cardiovascular outcomes, Circ. Cardiovasc. Interv. 7 (5) (2014) 645-655.
[13] A.J. Lansky, V.G. Ng, A. Maehara, G. Weisz, A. Lerman, G.S. Mintz, et al., Gender and the extent of coronary atherosclerosis, plaque composition, and clinical outcomes in acute coronary syndromes, J. Am. Coll. Cardiol. Img. 5 (3 Suppl) (2012) S62-S72.

[14] E. Canali, P. Masci, J. Bogaert, C. Bucciarelli Ducci, M. Francone, E. McAlindon, et al., Impact of gender differences on myocardial salvage and post-ischaemic left ventricular remodelling after primary coronary angioplasty: new insights from cardiovascular magnetic resonance, Eur. Heart J. Cardiovasc. Imaging 13 (11) (2012) 948-953.

[15] E.M. Bucholz, K.M. Strait, R.P. Dreyer, S.T. Lindau, G. D’Onofrio, M. Geda, et al., Editor's choice-sex differences in young patients with acute myocardial infarction: a VIRGO study analysis, Eur. Heart J. Acute Cardiovasc. Care 6 (7) (2017) 610-622.

[16] C. Wilkinson, O. Bebb, T.B. Dondo, T. Munyombwe, B. Casadei, S. Clarke, et al., Sex differences in quality indicator attainment for myocardial infarction: a nationwide cohort study, Heart 105 (7) (2019) 516-523.

[17] E. Cenko, M. van der Schaar, J. Yoon, S. Kedev, M. Valvukis, Z. Vasiljevic, et al., Sex-specific treatment effects after primary percutaneous intervention: a study on coronary blood flow and delay to hospital presentation, J. Am. Heart Assoc. 8 (4) (2019), e011190.

[18] F. Crea, P.G. Camici, C.N. Bairey Merz, Coronary microvascular dysfunction: an update, Eur. Heart J. 35 (17) (2014) 1101-1111.

[19] V.L. Murthy, M. Naya, V.R. Taqueti, C.R. Foster, M. Gaber, J. Hainer, et al., Effects of sex on coronary microvascular dysfunction and cardiac outcomes, Circulation 129 (24) (2014) 2518-2527.

[20] A.M. Maznyczka, D. Carrick, J. Carberry, K. Mangion, M. McEntegart, M.C. Petrie, et al., Sex-based associations with microvascular injury and outcomes after STsegment elevation myocardial infarction, Open Heart 6 (1) (2019), e000979.

[21] M. Moscucci, K.A. Fox, C.P. Cannon, W. Klein, J. Lopez-Sendon, G. Montalescot, et al., Predictors of major bleeding in acute coronary syndromes: the Global Registry of Acute Coronary Events (GRACE), Eur. Heart J. 24 (20) (2003) 1815-1823.

[22] P. Chichareon, R. Modolo, L. Kerkmeijer, M. Tomaniak, N. Kogame, K. Takahashi, et al., Association of sex with outcomes in patients undergoing percutaneous coronary intervention: a subgroup analysis of the GLOBAL LEADERS randomized clinical trial, JAMA Cardiol. 5 (1) (2020) 21-29.

[23] H. Jneid, G.C. Fonarow, C.P. Cannon, A.F. Hernandez, I.F. Palacios, A.O. Maree, et al., Sex differences in medical care and early death after acute myocardial infarction, Circulation 118 (25) (2008) 2803-2810.

[24] M. Walli-Attaei, P. Joseph, A. Rosengren, C.K. Chow, S. Rangarajan, S.A. Lear, et al., Variations between women and men in risk factors, treatments, cardiovascular disease incidence, and death in 27 high-income, middle-income, and low-income countries (PURE): a prospective cohort study, Lancet. 396 (10244) (2020) 97-109.

[25] M.G. Sutton, N. Sharpe, Left ventricular remodeling after myocardial infarction: pathophysiology and therapy, Circulation 101 (25) (2000) 2981-2988.

[26] J.F. Rodriguez-Palomares, J. Gavara, I. Ferreira-Gonzalez, F. Valente, C. Rios, J. Rodriguez-Garcia, et al., Prognostic value of initial left ventricular remodeling in patients with reperfused STEMI, J. Am. Coll. Cardiol. Img. 12 (12) (2019) 2445-2456.

[27] P. van der Bijl, R. Abou, L. Goedemans, B.J. Gersh, D.R. Holmes Jr., N. Ajmone Marsan, et al., Left ventricular post-infarct remodeling: implications for systolic function improvement and outcomes in the modern era, JACC Heart Fail. 8 (2) (2020) 131-140.

[28] M.S.J. Sutton, D. Lee, J.L. Rouleau, S. Goldman, T. Plappert, E. Braunwald, et al., Left ventricular remodeling and ventricular arrhythmias after myocardial infarction, Circulation 107 (20) (2003) 2577-2582.

[29] L. Bolognese, A.N. Neskovic, G. Parodi, G. Cerisano, P. Buonamici, G.M. Santoro, et al., Left ventricular remodeling after primary coronary angioplasty: patterns of left ventricular dilation and long-term prognostic implications, Circulation 106 (18) (2002) 2351-2357.

[30] S.D. Solomon, H. Skali, N.S. Anavekar, M. Bourgoun, S. Barvik, J.K. Ghali, et al., Changes in ventricular size and function in patients treated with valsartan, captopril, or both after myocardial infarction, Circulation 111 (25) (2005) 3411-3419.

[31] P.G. Masci, J. Ganame, M. Francone, W. Desmet, V. Lorenzoni, I. Iacucci, et al., Relationship between location and size of myocardial infarction and their reciprocal influences on post-infarction left ventricular remodelling, Eur. Heart J, 32 (13) (2011) 1640-1648.

[32] A. Lombardo, G. Niccoli, L. Natale, A. Bernardini, N. Cosentino, L. Bonomo, et al., Impact of microvascular obstruction and infarct size on left ventricular remodeling in reperfused myocardial infarction: a contrast-enhanced cardiac magnetic resonance imaging study, Int. J. Cardiovasc. Imaging 28 (4) (2012) 835-842.

[33] O. Husser, J.V. Monmeneu, J. Sanchis, J. Nunez, M.P. Lopez-Lereu, C. Bonanad, et al., Cardiovascular magnetic resonance-derived intramyocardial hemorrhage after STEMI: influence on long-term prognosis, adverse left ventricular remodeling and relationship with microvascular obstruction, Int. J. Cardiol. 167 (5) (2013) 2047-2054.

[34] P.H. Stone, D.S. Raabe, A.S. Jaffe, N. Gustafson, J.E. Muller, Z.G. Turi, et al., Prognostic significance of location and type of myocardial infarction: independent adverse outcome associated with anterior location, J. Am. Coll. Cardiol. 11 (3) (1988) 453-463.

[35] M.E. Hands, B.L. Lloyd, J.S. Robinson, Klerk Nd, P.L. Thompson, Prognostic significance of electrocardiographic site of infarction after correction for enzymatic size of infarction, Circulation 73 (5) (1986) 885-891. 
[36] H.M. Na, G.Y. Cho, J.M. Lee, M.J. Cha, Y.E. Yoon, S.P. Lee, et al., Echocardiographic predictors for left ventricular remodeling after acute ST elevation myocardial infarction with low risk group: speckle tracking analysis, J. Cardiovasc. Ultrasound 24 (2) (2016) 128-134.

[37] A.S. Bhatt, A.P. Ambrosy, E.J. Velazquez, Adverse remodeling and reverse remodeling after myocardial infarction, Curr. Cardiol. Rep. 19 (8) (2017) 71.

[38] S.D. Prabhu, N.G. Frangogiannis, The biological basis for cardiac repair after myocardial infarction, Circ. Res. 119 (1) (2016) 91-112.

[39] S.B. Ong, S. Hernandez-Resendiz, G.E. Crespo-Avilan, R.T. Mukhametshina, X. Y. Kwek, H.A. Cabrera-Fuentes, et al., Inflammation following acute myocardial infarction: multiple players, dynamic roles, and novel therapeutic opportunities, Pharmacol. Ther. 186 (2018) 73-87.

[40] V. Talman, H. Ruskoaho, Cardiac fibrosis in myocardial infarction-from repair and remodeling to regeneration, Cell Tissue Res. 365 (3) (2016) 563-581.

[41] J.A. Zavadzkas, R.E. Stroud, S. Bouges, R. Mukherjee, J.R. Jones, R.K. Patel, et al., Targeted overexpression of tissue inhibitor of matrix metalloproteinase-4 modifies post-myocardial infarction remodeling in mice, Circ. Res. 114 (9) (2014) $1435-1445$.

[42] D. Curley, B. Lavin Plaza, A.M. Shah, R.M. Botnar, Molecular imaging of cardia remodelling after myocardial infarction, Basic Res. Cardiol. 113 (2) (2018) 10.

[43] P. van der Bijl, R. Abou, L. Goedemans, B.J. Gersh, D.R. Holmes Jr., N. Ajmone Marsan, et al., Left ventricular remodelling after ST-segment elevation myocardial infarction: sex differences and prognosis, ESC Heart Fail. 7 (2) (2020) 474-481.

[44] C.S. Lam, M. McEntegart, B. Claggett, J. Liu, H. Skali, E. Lewis, et al., Sex differences in clinical characteristics and outcomes after myocardial infarction: insights from the Valsartan in Acute Myocardial Infarction Trial (VALIANT), Eur. J. Heart Fail. 17 (3) (2015) 301-312.

[45] I. Kosmidou, B. Redfors, H.P. Selker, H. Thiele, M.R. Patel, J.E. Udelson, et al., Infarct size, left ventricular function, and prognosis in women compared to men after primary percutaneous coronary intervention in ST-segment elevation myocardial infarction: results from an individual patient-level pooled analysis of 10 randomized trials, Eur. Heart J. 38 (21) (2017) 1656-1663.

[46] E.M. Bucholz, N.M. Butala, S.S. Rathore, R.P. Dreyer, A.J. Lansky, H M. Krumholz, Sex differences in long-term mortality after myocardial infarction: a systematic review, Circulation 130 (9) (2014) 757-767.

[47] M.A. Cavasin, Z. Tao, S. Menon, X.P. Yang, Gender differences in cardiac function during early remodeling after acute myocardial infarction in mice, Life Sci. 75 (18) (2004) 2181-2192.

[48] T. Shah, J.W. Weinsaft, S.R. Goldburg, R.B. Devereux, J. Kim, Abstract 16565 : impact of gender on myocardial infarction burden and post-myocardial infarction remodeling, Circulation 136 (suppl_1) (2017) A16565-A.

[49] L. Garber, T.C. McAndrew, E.S. Chung, B. Stancak, J.H. Svendsen, J. Monteiro, et al., Predictors of left ventricular remodeling after myocardial infarction in patients with a patent infarct related coronary artery after percutaneous coronary intervention (from the post-myocardial infarction remodeling prevention therapy [PRomPT] trial), Am. J. Cardiol. 121 (11) (2018) 1293-1298.

[50] D.L. Crabbe, K. Dipla, S. Ambati, A. Zafeiridis, J.P. Gaughan, S.R. Houser, et al. Gender differences in post-infarction hypertrophy in end-stage failing hearts, J. Am. Coll. Cardiol. 41 (2) (2003) 300-306.

[51] D. Nordlund, H. Engblom, J.-L. Bonnet, H.S. Hansen, D. Atar, D. Erlinge, et al, Gender but not diabetes, hypertension or smoking affects infarct evolution in STelevation myocardial infarction patients - data from the CHILL-MI, MITOCARE and SOCCER trials, BMC Cardiovasc. Disord. 19 (1) (2019) 161.

[52] J.G. Crilley, M. Farrer, Left ventricular remodelling and brain natriuretic peptide after first myocardial infarction, Heart 86 (6) (2001) 638-642.

[53] T. Hendriks, M.H.T. Hartman, P.J.J. Vlaar, N.H.J. Prakken, Y.M.Y. van der Ende, C.P.H. Lexis, et al., Predictors of left ventricular remodeling after ST-elevation myocardial infarction, Int. J. Cardiovasc. Imaging 33 (9) (2017) 1415-1423.

[54] J.C. Nilsson, B.A. Groenning, G. Nielsen, T. Fritz-Hansen, J. Trawinski, P. R. Hildebrandt, et al., Left ventricular remodeling in the first year after acute myocardial infarction and the predictive value of $\mathrm{N}$-terminal pro brain natriuretic peptide, Am. Heart J. 143 (4) (2002) 696-702.

[55] J. Hallén, J.K. Jensen, M.W. Fagerland, A.S. Jaffe, D. Atar, Cardiac troponin I for the prediction of functional recovery and left ventricular remodelling following primary percutaneous coronary intervention for ST-elevation myocardial infarction, Heart. 96 (23) (2010) 1892-1897.

[56] L.B. Daniels, A.S. Maisel, Cardiovascular biomarkers and sex: the case for women, Nat. Rev. Cardiol. 12 (10) (2015) 588-596.

[57] T. Lalem, L. Zhang, M. Scholz, R. Burkhardt, V. Saccheti, A. Teren, et al., Cyclin dependent kinase inhibitor $1 \mathrm{C}$ is a female-specific marker of left ventricular function after acute myocardial infarction, Int. J. Cardiol. 274 (2019) 319-325.

[58] K.Y. DeLeon-Pennell, A.J. Mouton, O.K. Ero, Y. Ma, R. Padmanabhan Iyer, E. R. Flynn, et al., LXR/RXR signaling and neutrophil phenotype following myocardial infarction classify sex differences in remodeling, Basic Res. Cardiol. 113 (5) (2018) 40.

[59] E.L. Kessler, M.R. Rivaud, M.A. Vos, T.A.B. van Veen, Sex-specific influence on cardiac structural remodeling and therapy in cardiovascular disease, Biol. Sex Differ. 10 (1) (2019) 7.

[60] J. Li, L. Ao, Y. Zhai, J.C. Cleveland, D.A. Fullerton, X. Meng, Gender disparity in the role of TLR2 in post-ischemic myocardial inflammation and injury, Int. J. Clin. Exp. Med. 8 (7) (2015) 10537-10547.

[61] G.G. Biondi-Zoccai, A. Abate, R. Bussani, D. Camilot, F.D. Giorgio, M.P. Marino, et al., Reduced post-infarction myocardial apoptosis in women: a clue to their different clinical course? Heart. 91 (1) (2005) 99-101.
[62] M. Piro, R. Della Bona, A. Abbate, L.M. Biasucci, F. Crea, Sex-related differences in myocardial remodeling, J. Am. Coll. Cardiol. 55 (11) (2010) 1057-1065.

[63] C. Stocco, Tissue physiology and pathology of aromatase, Steroids. 77 (1-2) (2012) 27-35.

[64] J.R. Bell, K.M. Mellor, A.C. Wollermann, W.T. Ip, M.E. Reichelt, S.J. Meachem, et al., Aromatase deficiency confers paradoxical postischemic cardioprotection, Endocrinology 152 (12) (2011) 4937-4947.

[65] C. Grohé, S. Kahlert, K. Löbbert, H. Vetter, Expression of oestrogen receptor alpha and beta in rat heart: role of local oestrogen synthesis, J. Endocrinol. 156 (2) (1998) R1-R7.

[66] S. Salerni, S. Di Francescomarino, C. Cadeddu, F. Acquistapace, S. Maffei, S. Gallina, The different role of sex hormones on female cardiovascular physiology and function: not only oestrogens, Eur. J. Clin. Investig. 45 (6) (2015) 634-645.

[67] M. van Eickels, C. Grohé, J.P. Cleutjens, B.J. Janssen, H.J. Wellens, P. A. Doevendans, 17beta-estradiol attenuates the development of pressure-overload hypertrophy, Circulation 104 (12) (2001) 1419-1423.

[68] F.A. Babiker, L.J. De Windt, M. van Eickels, V. Thijssen, R.J. Bronsaer, C. Grohe, et al., 17beta-estradiol antagonizes cardiomyocyte hypertrophy by autocrine/ paracrine stimulation of a guanylyl cyclase A receptor-cyclic guanosine monophosphate-dependent protein kinase pathway, Circulation 109 (2) (2004) 269-276.

[69] A. Pedram, M. Razandi, M. Aitkenhead, E.R. Levin, Estrogen inhibits cardiomyocyte hypertrophy in vitro. Antagonism of calcineurin-related hypertrophy through induction of MCIP1, J. Biol. Chem. 280 (28) (2005) 26339-26348.

[70] A. Pedram, M. Razandi, R. Narayanan, J.T. Dalton, T.A. McKinsey, E.R. Levin, Estrogen regulates histone deacetylases to prevent cardiac hypertrophy, Mol. Biol. Cell 24 (24) (2013) 3805-3818.

[71] R.D. Patten, I. Pourati, M.J. Aronovitz, A. Alsheikh-Ali, S. Eder, T. Force, et al., 17 Beta-estradiol differentially affects left ventricular and cardiomyocyte hypertrophy following myocardial infarction and pressure overload, J. Card. Fail. 14 (3) (2008) 245-253.

[72] G. Kararigas, B.T. Nguyen, L.C. Zelarayan, M. Hassenpflug, K. Toischer, H. Sanchez-Ruderisch, et al., Genetic background defines the regulation of postnatal cardiac growth by $17 \beta$-estradiol through a $\beta$-catenin mechanism, Endocrinology 155 (7) (2014) 2667-2676.

[73] J.A. Stewart Jr., D.O. Cashatt, A.C. Borck, J.E. Brown, W.E. Carver, 17betaestradiol modulation of angiotensin II-stimulated response in cardiac fibroblasts, J. Mol. Cell. Cardiol. 41 (1) (2006) 97-107.

[74] A. Pedram, M. Razandi, F. O'Mahony, D. Lubahn, E.R. Levin, Estrogen receptorbeta prevents cardiac fibrosis, Mol. Endocrinol. 24 (11) (2010) 2152-2165.

[75] T.M. Lee, S.Z. Lin, N.C. Chang, Membrane ERalpha attenuates myocardial fibrosis via RhoA/ROCK-mediated actin remodeling in ovariectomized female infarcted rats, J. Mol. Med. 92 (1) (2014) 43-51.

[76] G. Kararigas, D. Fliegner, J.A. Gustafsson, V. Regitz-Zagrosek, Role of the estrogen/estrogen-receptor-beta axis in the genomic response to pressure overload-induced hypertrophy, Physiol. Genomics 43 (8) (2011) 438-446.

[77] D. Camper-Kirby, S. Welch, A. Walker, I. Shiraishi, K.D. Setchell, E. Schaefer, et al., Myocardial Akt activation and gender: increased nuclear activity in females versus males, Circ. Res. 88 (10) (2001) 1020-1027.

[78] R.D. Patten, I. Pourati, M.J. Aronovitz, J. Baur, F. Celestin, X. Chen, et al., 17betaestradiol reduces cardiomyocyte apoptosis in vivo and in vitro via activation of phospho-inositide-3 kinase/Akt signaling, Circ. Res. 95 (7) (2004) 692-699.

[79] H. Hamada, M.K. Kim, A. Iwakura, M. Ii, T. Thorne, G. Qin, et al., Estrogen receptors alpha and beta mediate contribution of bone marrow-derived endothelial progenitor cells to functional recovery after myocardial infarction, Circulation 114 (21) (2006) 2261-2270.

[80] S. Frantz, K. Hu, J. Widder, B. Weckler, H. Scheuermann, J. Bauersachs, et al., Detrimental effects of testosterone on post-myocardial infarction remodelling in female rats, J. Physiol. Pharmacol. 58 (4) (2007) 717-727.

[81] R.A. Fernandes Correa, R.F. Ribeiro Junior, S.B. Oliveira Mendes, P.M. Dos Santos, M.V.A. da Silva, D.F. Silva, et al., Correction: testosterone deficiency reduces the effects of late cardiac remodeling after acute myocardial infarction in rats, PLoS One 14 (12) (2019), e0226664.

[82] M.A. Cavasin, Z.Y. Tao, A.L. Yu, X.P. Yang, Testosterone enhances early cardiac remodeling after myocardial infarction, causing rupture and degrading cardiac function, Am. J. Physiol. Heart Circ. Physiol. 290 (5) (2006) H2043-H2050.

[83] P.R. Crisostomo, M. Wang, G.M. Wairiuko, E.D. Morrell, D.R. Meldrum, Brie exposure to exogenous testosterone increases death signaling and adversely affects myocardial function after ischemia, Am. J. Physiol. Regul. Integr. Comp. Physiol. 290 (5) (2006) R1168-R1174.

[84] C. Huang, H. Gu, W. Zhang, J.L. Herrmann, M. Wang, Testosterone-down regulated Akt pathway during cardiac ischemia/reperfusion: a mechanism involving BAD, Bcl-2 and FOXO3a, J. Surg. Res. 164 (1) (2010) e1-11.

[85] B.W. Florijn, R. Bijkerk, E.P. van der Veer, A.J. van Zonneveld, Gender and cardiovascular disease: are sex-biased microRNA networks a driving force behind heart failure with preserved ejection fraction in women? Cardiovasc. Res. 114 (2) (2018) 210-225.

[86] T. Lalem, Y. Devaux, Circulating microRNAs to predict heart failure after acute myocardial infarction in women, Clin. Biochem. 70 (2019) $1-7$.

[87] J.T. Lee, M.S. Bartolomei, X-inactivation, imprinting, and long noncoding RNAs in health and disease, Cell. 152 (6) (2013) 1308-1323.

[88] C. Sun, H. Liu, J. Guo, Y. Yu, D. Yang, F. He, et al., MicroRNA-98 negatively regulates myocardial infarction-induced apoptosis by down-regulating Fas and caspase-3, Sci. Rep. 7 (1) (2017) 7460. 
[89] Y. Yang, T. Ago, P. Zhai, M. Abdellatif, J. Sadoshima, Thioredoxin 1 negatively regulates angiotensin II-induced cardiac hypertrophy through upregulation of miR-98/let-7, Circ. Res. 108 (3) (2011) 305-313.

[90] B. Ibanez, S. James, S. Agewall, M.J. Antunes, C. Bucciarelli-Ducci, H. Bueno, et al., 2017 ESC guidelines for the management of acute myocardial infarction in patients presenting with ST-segment elevation: the task Force for the management of acute myocardial infarction in patients presenting with STsegment elevation of the European Society of Cardiology (ESC), Eur. Heart J. 39 (2) (2017) 119-177.

[91] X. Jin, C. Chandramouli, B. Allocco, E. Gong, C.S.P. Lam, L.L. Yan, Women's participation in cardiovascular clinical trials from 2010 to 2017, Circulation 141 (7) (2020) 540-548.

[92] S. Arora, G.A. Stouffer, A.M. Kucharska-Newton, A. Qamar, M. Vaduganathan, A. Pandey, et al., Twenty year trends and sex differences in young adults hospitalized with acute myocardial infarction, Circulation 139 (8) (2019) 1047-1056.

[93] S.A.E. Peters, L.D. Colantonio, H. Zhao, V. Bittner, Y. Dai, M.E. Farkouh, et al. Sex differences in high-intensity statin use following myocardial infarction in the United States, J. Am. Coll. Cardiol. 71 (16) (2018) 1729-1737.

[94] P. Cirillo, L. Di Serafino, G. Patti, E. Antonucci, P. Calabrò, P. Gresele, et al., Gender-related differences in antiplatelet therapy and impact on 1-year clinical outcome in patients presenting with ACS: the START ANTIPLATELET registry, Angiology 70 (3) (2019) 257-263.

[95] W.T. Wang, S.K. James, T.Y. Wang, A review of sex-specific benefits and risks of antithrombotic therapy in acute coronary syndrome, Eur. Heart J. 38 (3) (2016) 165-171.

[96] R.M. Kanashiro-Takeuchi, B. Heidecker, G. Lamirault, J.W. Dharamsi, J.M. Hare, Sex-specific impact of aldosterone receptor antagonism on ventricular remodeling and gene expression after myocardial infarction, Clin. Transl. Sci. 2 (2) (2009) 134-142.

[97] R.S. Vasan, J.C. Evans, M.G. Larson, P.W.F. Wilson, J.B. Meigs, N. Rifai, et al., Serum aldosterone and the incidence of hypertension in nonhypertensive persons, N. Engl. J. Med. 351 (1) (2004) 33-41.

[98] H.M. Boardman, L. Hartley, A. Eisinga, C. Main, M. Roqué i Figuls, X. Bonfill Cosp, et al., Hormone therapy for preventing cardiovascular disease in postmenopausal women, Cochr. Datab. Syst. Rev. (3) (2015) Cd002229.

[99] N. Froese, H. Wang, C. Zwadlo, Y. Wang, A. Grund, A. Gigina, et al., Antiandrogenic therapy with finasteride improves cardiac function, attenuates remodeling and reverts pathologic gene-expression after myocardial infarction in mice, J. Mol. Cell. Cardiol. 122 (2018) 114-124.

[100] A. Galati, M. Piccoli, N. Tourkmani, L. Sgorbini, A. Rossetti, L. Cugusi, et al, Cardiac rehabilitation in women: state of the art and strategies to overcome the current barriers, J. Cardiovasc. Med. (Hagerstown) 19 (12) (2018) 689-697. 